Laise Carla Lima Verde Rodrigues

Joseana Rocha

André Wladimir de Oliveira Janoski

Alan F. Santos

Luis Fernando Rojas Terrazas

Correspondencia a:

Centro de investigación medicina UNITEPC. CIMU Cochabamba - Bolivia

laise_carla@unitepc-mail. com

joseana_rocha@unitepc-mail.com

andre_wladimir@unitepc-mail.com

alanf_santos@unitepc-mail.com

Irojas_investigacion@unitepc-mail.com

Procedencia y arbitraje: No comisionado, sometido a arbitraje externo

Recibido para publicación: 16 de mayo del 2018 Aceptado para publicación: 31 de julio del 2018

Citar como:

$\mathrm{Re} \mathrm{Ci} \mathrm{Sa}$ UNI

2018;5(2):8-15

\section{ANÁLISIS MICROBIOLOGICO DE LA CHICHA EN EL MUNICIPIO DE COLCAPIRHUA - COCHABAMBA / BO.}

\section{MICROBIOLOGICAL ANALYSIS OF THE CHICHA IN THE MUNICIPALITY OF COLCAPIRHUA - COCHABAMBA / BO. \\ ANÁLISE MICROBIOLÓGICA DA CHICHA NO MUNICÍPIO DE COLCAPIRHUA - COCHABAMBA / BO.}

\section{Resumen.}

La chicha es una bebida alcohólica derivada principalmente de la fermentación no destilada del maíz y otros cereales originarios de América, su cualidad puede ser influenciada por diversos factores enzimáticos, químicos, físicos y microbiológicos. EsteestudiobuscóevaluarlacalidadmicrobiológicadelachichacomercializadaenelmunicipiodeColcapirhuaCochabamba-Bolivia. Paralarecoleccióndelasmuestras, fueronseleccionadoslosestablecimientoscomercialesqueexpendenestabebida. 51 muestras fueron tomadas y transportadas al laboratorio de microbiología de Universidad Técnica Privada Cosmos, donde fueron analizados. Los resultados: 5 presentaron E. coli, 44 otras bacterias Gram negativas, 2 muestras estaban ausentes de microorganismos. Se destaca, con base a los resultados que hay deficiencia en la higiene durante la etapa de preparación y/o manipulación de la bebida que compromete la seguridad microbiológica, sugiriendo mayores cuidados en las buenas prácticas de higiene personal, principalmente de los manipuladores y también la higienización de los utensilios. Estas prácticas de higiene sanitaria deben ser implantadas y monitoreadas durante la producción y manipulación de alimentos.

Palabras claves: Chicha, análisis microbiológicos, E. coli.

\section{Summary.}

Chicha is an alcoholic beverage derived mainly from the non-distilled fermentation of corn and other cereals originating in America, its quality can be influenced by various enzymatic, chemical, physical and microbiological factors.

This study sought to evaluate the microbiological quality of the chicha marketed in the municipality of Colcapirhua Cochabamba-Bolivia.

For the collection of the samples, the commercial establishments that sell this drink were selected. 51 samples were taken and transported to the microbiology laboratory of Universidad Técnica Privada Cosmos, where they were analyzed.

The results: 5 presented E. coli, 44 other Gram negative bacteria, 2 samples were absent from microorganisms.

It is highlighted, based on the results that there is a deficiency in hygiene during the preparation and / or handling stage of the 
drink that compromises microbiological safety, suggesting greater care in good personal hygiene practices, mainly of the manipulators and also the sanitation of utensils. These sanitary hygiene practices must be implemented and monitored during the production and handling of food.

Keywords: Chicha, microbiological analysis, E. coli.

\section{Resumo.}

Chicha é uma bebida alcoólica derivada principalmente da fermentação não destilada do milho e outros cereais tipicos das Américas, sua qualidade pode ser influenciada por vários fatores enzimáticos, químicos, físicos e microbiológicos.

Este estudo buscou avaliar a qualidade microbiológica da chicha comercializada no município de Colcapirhua, Cochabamba-Bolívia.

Para a coleta das amostras, foram selecionados os estabelecimentos comerciais que vendem essa bebida. Foram coletadas 51 amostras e transportadas para o laboratório de microbiologia da Universidade Técnica Privada Cosmos, onde foram analisadas.

Resultados: 5 amostras estavam contaminadas com E. coli, 44 apresentaram outras bactérias Gram negativas e somente 2 amostras não apresentaram microrganismos. Destaca-se, com base nos resultados que os hábitos de higiene são deficientes durante o estágio de preparação e/ou manipulação da bebida o que compromete a segurança microbiológica. Os resultados sugerem a necesidade de uma melhora na higiene sanitaria e pessoal dos produtores, assim como, o saneamento dos utensílios. Estas práticas de higiene sanitária devem ser implementadas e monitoradas durante a produção e manuseio de alimentos.

Palavras-chave: Chicha, análise microbiológica, E. coli.

\section{INTRODUCCIÓN}

Etimológicamente la palabra chicha tiene muchas acepciones: Del Maya = chiboca; de Chac $=$ mascar; Chicháa $=$ Ilenar de agua; Zicha = agua fresca; en Keshuwa = licuado. ${ }^{17}$

Se obtenía masticando y escupiendo los granos de maíz de la mazorca recién cosechada en una mucura, las enzimas presentes en la saliva transformaban el almidón del maíz en azúcar que luego se fermenta por acción de las bacterias.

Una vez llena la mucura, cierran frenéticamente y es puesto a reposar a la sombra, fermentada la chicha filtran y envasan para su posterior consumo. ${ }^{15}$

La chicha es una bebida alcohólica derivada principalmente de la fermentación no destilada del maíz y otros cereales originarios de América. ${ }^{17}$

En el siglo XIX, seguía la elaboración de la chicha y el consumo masivo. Llano y Campuzano describen una chicheria: "La entrada era en muchos casos, por un zaguán, desde el cual se llegaba a un cuarto oscuro, sólo alumbrado por la leña de la cocina y una que otra vela de cebo, la única entrada de aire era la puerta, la cocina quebrada en el mismo cuarto, carecía de baños, el piso de tierra y las paredes de adobe, cubiertas rústicamente de barro, negras de humo". ${ }^{12}$

El tomar la chicha no solo es costumbre, sino cumple una función social, un punto de encuentro de los indígenas, mestizos, clase media y distinguidas personalidades, es 
un lugar de información y culminación de convenios económicos, espacio para divertirse, en definitiva, se convierte en un refugio de identidad social. ${ }^{17}$

En la actualidad, la chicha se elabora en Bolivia en el marco establecido por la ley $\mathrm{N}^{\circ}$ 259 (Ley de 11/07/2012), decreta ley de Control de expendió y consumo de bebidas alcohólicas. Reglamentada por la ley No 557 (Ley promulgada el 30/04/2015) que declara patrimonio cultural tangible e intangible del Departamento de Cochabamba a la Aqha o chicha. ${ }^{10,11 .}$

Para la elaboración de chicha, el ambiente debe estar limpio, cántaros, wirkhis, peroles, latas, baldes, tutumas y otros accesorios, deben ser revisados rigurosamente. ${ }^{17}$

El concepto de chicha permaneció asociado preferentemente a la bebida de maíz fermentado: "Bebida fermentada hecha de maíz, algarroba, uva, molle, chalchal, etc. La más común es el maíz" (Ozán, 2006: 200). Conceptos parecidos ofrece el Diccionario Folklórico Argentino. ${ }^{3}$

Mientras en la región andina el concepto de chicha se mantuvo tradicionalmente asociado a la bebida de maíz fermentado, Posteriormente, con la incorporación de las plantas europeas se extendió la costumbre de elaborar bebidas alcohólicas a partir de frutas. ${ }^{8}$

De acuerdo con Román, J. C. (2016), describe que según la concepción de los pueblos, no es sólo una bebida alcohólica presente en rituales, fiestas y otros. También juega un papel preponderante dentro de la medicina tradicional, vamos mencionar muchas ellas.

- Se emplea como dilatador durante las labores de parto.

- Para las afecciones pulmonares (resfrío).

- El control de la fiebre.

- La chicha batida en huevo criollo cura la afección de los riñones.

- Cura síntomas de temblores, calentando una llave antigua en el fogón.

- Se usa como tónico.

El consumo afecta al sistema nervioso central, ocasionando pérdida de equilibrio, desaparece la capacidad de raciocinio. Puede dañar los lóbulos frontales, pérdida de control y conciencia, disminuye la capacidad cognitiva. ${ }^{17}$

Y es que la chicha, sobre todo la nueva, era señalada como culpable de las tasas de alcoholismo y mal comportamiento de la época, coincidente con la demonización del consumo de alcohol al transformarse en un problema para la salud pública. ${ }^{5}$

En la actualidad, la chicha destaca por su carácter artesanal y su consumo es notable en el marco de las festividades como: matrimonios, bautismos, cabo de año, de gran importancia como las fiestas patrias y Urkupiña. Si bien también es consumida durante todo el año.

Las alteraciones microbiológicas son indeseables en cualquier tipo de alimento, así como la presencia de patógenos y microorganismos indicadores de malas condiciones higiénico sanitarias. De esta forma, por la demanda creciente de consumo de chicha se hace indispensable la realización de investigaciones para evaluar su calidad microbiológica.

En este trabajo tenemos la intención de analizar las características microbiológicas 
de la chicha comercializados en el municipio de Colcapirhua, departamento de Cochabamba Bolivia.

\section{MATERIALES Y MÉTODO}

Las muestras de chicha utilizadas en este trabajo fueron recolectadas en diferentes locales de expendió de esta bebida del municipio de Colcapirhua. De cada local se obtuvieron varias muestras en el mes de diciembre de 2017, totalizando 51 muestras $\left(\mathrm{N}^{\circ}=51\right)$ identificadas con un número y llevadas al Laboratorio de Microbiología de la Universidad Técnica Privada Cosmos, campus Florida norte, carrera de medicina.

La chicha fue recogida en frascos plásticos estériles de $400 \mathrm{ml}$, cerrados y acondicionados en caja de material isotérmico, y transportados al laboratorio.

La cantidad de chicha recogido fue de 150-200 ml. El tiempo transcurrido entre la toma de muestras y el inicio de su examen microbiológico, en ningún caso supero los 45 minutos.

En el laboratorio, se preparó 51 placas de Petri estériles que contenían $15 \mathrm{ml}$ de agar EMB. El Agar Eosin-metilene Blue. El cual fue preparado según la técnica inicialmente por Holt-Harris y Teague en 1916.

Después de la homogeneización de la chicha y solidificación del agar, se procedió a la siembra esparciendo la muestra sobre la superficie del medio, con mango de níquel-cromo esterilizado e incubado a $37^{\circ} \mathrm{C}$ durante 24 horas, después se observaron las colonias.

En estas placas, se observó la ausencia de colonias, y/o la presencia de colonias negras o claras con centro negro en el agar eosina azul de metileno a fin de presentar resultados cualitativos positivos o negativos de bacterias en la chicha. ${ }^{13}$

\section{RESULTADOS Y DISCUSIÓN}

La chicha es un producto típico y popular, se trata de una bebida de singular tradición y ampliamente difundida en las masas populares, sobre todo en las celebraciones de fin de cosecha, carnaval y fiestas patrias. Esta bebida típica no ha sido estudiada hasta el momento con suficiente profundidad por la academia. Los trabajos de Claudio Gay (1855) trazaron un perfil un tanto despectivo de este producto y sentaron las bases de su valoración negativa, reiterada después por los autores posteriores (Couyoumdjian, 2006). ${ }^{4}$

Según el Pinheiro et al. (2006), todo y cualquier género alimentario debe presentar un valor nutricional adecuado, buena apariencia y buenas condiciones de higiene, ya que la alimentación completa nutricionalmente exige un equilibrio de esas características. ${ }^{16}$

En la Tabla 1, se encuentran los resultados de las determinaciones hechas a partir de cada una de las 51 muestras de chicha, cosechadas en diferentes puestos del municipio de Colcapirhua. 
Tabla 1:

Presencia de microorganismos determinantes para cada una de las muestras de chicha cosechadas en diferentes puestos del municipio de Colcapirhua.

\begin{tabular}{|c|c|c|}
\hline Muestra & $\begin{array}{c}\text { Presencia de } \\
\text { Escherichia coli }\end{array}$ & $\begin{array}{c}\text { Presencia de otras } \\
\text { bacterias Gram-nega- } \\
\text { tivas }\end{array}$ \\
\hline 1 & - & ++ \\
\hline 2 & - & +++ \\
\hline 3 & - & + \\
\hline 4 & - & ++ \\
\hline 5 & - & ++ \\
\hline 6 & - & +++ \\
\hline 7 & - & ++ \\
\hline 8 & - & +++ \\
\hline 9 & + & +++ \\
\hline 10 & + & +++ \\
\hline 11 & - & ++++ \\
\hline 12 & - & ++++ \\
\hline 13 & - & ++ \\
\hline 14 & - & ++++ \\
\hline 15 & - & ++++ \\
\hline 16 & - & ++++ \\
\hline 17 & - & ++ \\
\hline 18 & - & +++ \\
\hline 19 & - & ++++ \\
\hline 20 & - & ++++ \\
\hline 21 & - & ++++ \\
\hline 22 & + & +++ \\
\hline 23 & - & +++ \\
\hline 24 & - & ++++ \\
\hline 25 & - & +++ \\
\hline 26 & - & +++ \\
\hline 27 & + & ++ \\
\hline 28 & + & + \\
\hline 29 & - & ++++ \\
\hline 30 & - & +++ \\
\hline 31 & - & +++ \\
\hline 32 & - & + \\
\hline 33 & - & + \\
\hline 34 & - & + \\
\hline 35 & - & ++++ \\
\hline
\end{tabular}




\begin{tabular}{ccc}
36 & - & - \\
37 & - & +++ \\
38 & - & ++++ \\
39 & - & ++++ \\
40 & - & ++++ \\
41 & - & + \\
42 & - & ++ \\
43 & - & - \\
44 & - & ++++ \\
45 & - & ++++ \\
46 & - & +++ \\
47 & - & ++++ \\
48 & - & ++++ \\
49 & - & ++++ \\
50 & - & ++ \\
51 & - & + \\
\hline
\end{tabular}

Leyenda: (-) ausencia de microorganismo por placas incubadas, (+) presencia de microorganismo por placas incubadas.

\section{Fuente: los autores.}

Según el análisis en 2 muestras no se constató el crecimiento de ningún microorganismo. De las muestras contaminadas, 44 muestras evaluadas no constataron el crecimiento de Escherichia coli, pero presentó un resultado significativo en la formación de otras colonias de bacterias Gram negativas, en los 5 restantes fue positivas y expresiva la contaminación por Escherichia coli.

El conteo de bacterias aerobias mesófilas se utiliza para indicar la calidad sanitaria de los alimentos, y un elevado número de estos microorganismos es indicador de insalubridad, aunque los patógenos estén ausentes y que no hayan ocurrido alteraciones en las condiciones de la bebida. Todas las bacterias patógenas de origen alimentario son mesófilas. Sin embargo, un número elevado de mesófilos que crecen a la temperatura ambiente significa que hubo condiciones para que estos patógenos se multiplicaran. ${ }^{6}$

Las enterobacterias, en general, no se desarrollan en valores de $\mathrm{pH}$ inferiores a 4,5 y su tiempo de supervivencia suele ser variable, a pesar de que pueden ser aisladas de jugos recién extraídos. ${ }^{9}$

De acuerdo con Franco y Landgraf (2007), entre los parámetros más importantes que determinan la calidad de un alimento, sin duda están aquellos que definen sus características microbiológicas, lo que permite evaluarlo en cuanto a las condiciones de procesamiento, almacenamiento, distribución para consumo, vida útil y riesgos para la salud población. ${ }^{6}$

Los alimentos son fácilmente contaminados por microorganismos en la preparación y manipulación, sirviendo como medio para el crecimiento de microorganismos, pudiendo incluso cambiar sus características físicas, químicas y organolépticas llevándolo al deterioro. ${ }^{1}$ 
La calidad de la chicha puede ser influenciada por diferentes factores enzimáticos, químicos, físicos y microbiológicos. La influencia de éstos promueve alteraciones en el producto comprometiendo las características organolépticas y nutricionales. Estas modificaciones son susceptibles de ocurrir en las diferentes etapas de la fabricación hasta el consumo final. ${ }^{2}$

Las condiciones higiénico sanitarias inadecuadas durante el proceso de fabricación son los principales indicios que comprometen la seguridad microbiológica del producto. ${ }^{14}$

Otro factor importante en la contaminación de los alimentos es la deficiencia en la capacitación de los manipuladores y vendedores, pues la falta de higiene o hábitos inadecuados de los mismos puede comprometer la calidad del producto.

La exposición de la chicha a temperatura ambiente durante un tiempo prolongado, vasos, tutumas y jarras utilizados en la comercialización almacenados en lugares inadecuados expuestos al aire libre y la manipulación de estos sin el uso de guantes, son actitudes que favorecen la proliferación patógenos y deteriorantes. ${ }^{13,18}$

\section{CONCLUSIONES}

Los resultados obtenidos mostraron que, de las cincuenta y un muestras analizadas, dos no mostraron crecimiento de microorganismos. En contraste las demás muestras presentaron crecimiento, de estas cinco presentaron Escherichia coli.

Con este trabajo pretendemos apoyar con un control para contribuir con las medidas sanitarias adecuadas, con el propósito de reducir el grado de contaminación, y se cumpla con procedimientos de limpieza de los equipos y utensilios utilizados, y también en la mejora de las condiciones de almacenamiento.

Las medidas para el control de calidad de alimentos se hacen necesarias, entre las cuales se destacan el de los profesionales involucrados en la producción de chicha y monitorio de las condiciones de los manipuladores.

\section{BIBLIOGRAFÍA}

1. Cunha, M. A. Métodos de detecção de microrganismos indicadores. Saúde e Ambiente em Revista, Duque de Caxias, v. 1, n. 1, p. 09-13, jan./jun. 2006.

2. Corrêa-Neto, R. S.; Faria, J. A. F. Fatores que influem na qualidade do suco de Iaranja. Cienc. Tecnol. Aliment., Campinas, v. 19, n. 1, p. 153-161, 1999.

3. Coluccio, F. Diccionario folklórico argentino. Edición popular: Buenos Aires, Luis Lasserre y Cía. Editores, 2 tomos, 510 pp. 1964.

4. Del Pozo, J. Historia del vino chileno. Desde la época colonial hasta hoy. LOM Ediciones, Santiago, Chile, 306 pp. 2014.

5. Ferrari, A. Borrachos eran los de antes. El vino como problema sociocultural y político en San Juan, Argentina, 1880-1910 Revista Iberoamericana de Viticultura, Agroindustria y Ruralidad (RIVAR), 1(3): 53-68. 2014.

6. Franco, B. D. G. M.; Landgraf, M. Microrganismos indicadores. In: Microbiologia dos alimentos. São Paulo: Atheneu, 2007. cap. 3, p. 27-31.

7. Holt-Harris, J.E., and O. Teague. 1916. A new culture medium for the isolation of Bacillus typhosus from stools. J. Infect. Dis. 18:596-600. 
8. Lacoste, Pablo et al . Historia de la chicha de uva: un producto típico en Chile. Idesia, Arica, v. 33, n. 2, p. 87-96, mayo 2015. Disponible en < https://scielo.conicyt.cl/scielo.php?script=sci_arttext\&pid=S071834292015000200011\&lng=es\&nrm=iso > .accedidoen 29 jun. 2018. http://dx.doi.org/10.4067/S0718-34292015000200011

9. Leitão, M.F.F., Delazari, I., Uboldieiroa, M.N., Arima, A.K. Avaliação de sucos, refrigerantes, refrescos, néctares e xaropes em face dos padrões microbiológicos brasileiros. Boletim do ITAL, Campinas, v. 49, p. 75-91, jan./fev. 1977.

10. Ley n² 259 del 11/07/2012. Gobierno Autónomo Departamental de Cochabamba. Bolivia. Acceso en 29/06/2018 as 14hs. Disponible en http://autonomias.gobernacionlapaz.com/leyes-y-normativas-cochabamba/

11. Ley $n^{\circ} 557$ del 30/04/2015. Asemblea Legislativa Departamental de Cochabamba. Bolivia. Acceso en 29/06/2018 as 15hs. Disponible en http://autonomias.gobernacionlapaz.com/leyes-y-normativas-cochabamba/

12. Llano, Maria Clara; Campuzano, Marcela. La chicha, una bebida fermentada a taves de la história. ICAN Calculotura. Bogotá Colombia, 1994.

13. Nascimento, D.; Furlanetto, S. M. P. Determinação quantitativa de grupos de bactérias em sucos de laranja ao natural. Rev. Saúde Pública, São Paulo, v. 15, p. 221-235, 1981.

14. Oliveira, J. C. et al. Características microbiológicas do suco de laranja in natura. Cienc. Tecnol. Aliment., Campinas, v. 26, n. 2, p. 241-245, 2006.

15. Perez, Oskar Andres Riveros. Chicha. http://chichalandia.blogspot.com/. acceso en 13/06/2018 ás 17:00hs.

16. Pinheiro A. M.; Fernandes A. G.; Fai, A. E. C.; Prado G. M.; Sousa P. H. M.; Maia G. A. Avaliação química, físico-química e microbiológica de sucos de frutas integrais: abacaxi, caju e maracujá. Revista Ciência e Tecnologia de Alimentos, Campinas, v. 26, n. 1, p. 98-103, jan./mar. 2006.

17.17. Román, Juan Clavijo. La chicha en el valle de Cochabamba. Serie: Identidades y costumbres regionales. Quillacollo - Cochabamba. Editorial Tharsis. 2016.

18. Ruschel, C. K. et al. Qualidade microbiológica e físico-química de sucos de laranja comercializados nas vias públicas de Porto Alegre/RS. Cienc. Tecnol. Aliment., Campinas, v. 2, n. 1, p. 94-97, 2001. 